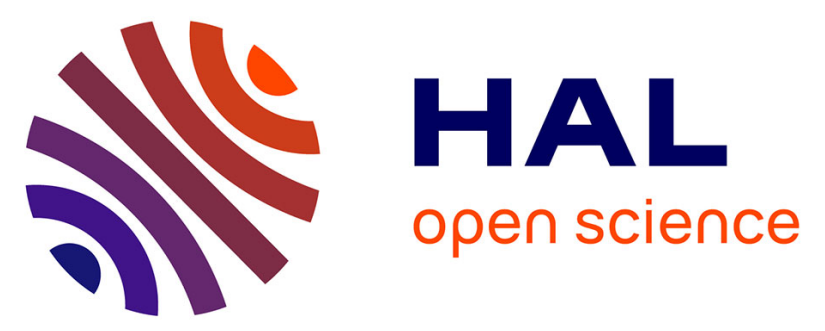

\title{
The Systematic Integration of Stakeholders into Factory Planning, Construction, and Factory Operations to Increase Acceptance and Prevent Disruptions
}

\author{
Uwe Dombrowski, Alexander Karl, Colette Vogeler, Nils Bandelow
}

\section{- To cite this version:}

Uwe Dombrowski, Alexander Karl, Colette Vogeler, Nils Bandelow. The Systematic Integration of Stakeholders into Factory Planning, Construction, and Factory Operations to Increase Acceptance and Prevent Disruptions. IFIP International Conference on Advances in Production Management Systems (APMS), Sep 2019, Austin, TX, United States. pp.539-546, 10.1007/978-3-030-29996-5_62 . hal-02460452

\section{HAL Id: hal-02460452 \\ https://hal.inria.fr/hal-02460452}

Submitted on 30 Jan 2020

HAL is a multi-disciplinary open access archive for the deposit and dissemination of scientific research documents, whether they are published or not. The documents may come from teaching and research institutions in France or abroad, or from public or private research centers.
L'archive ouverte pluridisciplinaire HAL, est destinée au dépôt et à la diffusion de documents scientifiques de niveau recherche, publiés ou non, émanant des établissements d'enseignement et de recherche français ou étrangers, des laboratoires publics ou privés. 


\title{
The systematic integration of stakeholders into factory planning, construction, and factory operations to increase acceptance and prevent disruptions
}

\author{
Uwe Dombrowski ${ }^{1}$, Alexander Karl ${ }^{1 *}$, Colette Vogeler ${ }^{2}$, Nils Bandelow ${ }^{2}$ \\ ${ }^{1}$ Institute for Advanced Industrial Management (IFU) \\ ${ }^{2}$ Chair of Comparative Politics and Public Policy (CoPPP) \\ Technische Universität Braunschweig, Langer Kamp 19, 38106 Braunschweig, Germany \\ *Corresponding author. Tel: +49 531391 2713, E-mail: a.karl@tu-bs.de
}

\begin{abstract}
The construction of factories is based on the factory planning process. A new construction of factories or their expansion represents a significant investment decision for companies. Therefore, it is necessary from an economic point of view to allow a trouble-free flow. Current trends, such as urban factories, increase the likelihood of conflict with external stakeholders. In many cases, this means high additional costs and risks for the companies concerned. The evaluation of current case studies shows that ignoring individual stakeholders during planning can lead to delays or, in the worst-case scenario, to the shutdown of the factory project. The aim of this article is to present the current state of stakeholder integration in factory planning, construction, and factory operations in research and practice. Based on the results of a research project in Germany, studies are presented and necessary fields of action identified. Subsequently, a concept is derived that facilitates the systematic and project-specific integration of stakeholders into the factory planning process.
\end{abstract}

Keywords: factory planning process, stakeholder participation.

\section{Introduction}

The construction of large infrastructure or building projects often leads to conflict with citizens or citizen groups. These conflicts have repeatedly escalated, culminating in violent behavior. A prominent example is the conflict surrounding the German infrastructure and railway project "Stuttgart 21 ", which was accompanied by massive public - and partly violent - protests. Tens of thousands of citizens mobilized against the project, demanding an end to the construction works. Although the reasons for the resistance against the project are manifold, many opponents questioned the legitimacy of the project and even called for public participation in the decision-making process [1]. The public resistance even contributed to a change of the federal government and to the holding of a referendum on the project. Following the referendum, in which a majority voted to continue with the infrastructure project, the manifestations lost momentum [2]. The case of "Stuttgart 21" exemplifies how citizens increasingly demand participation in decisions over infrastructure and building projects. In many countries, policymakers 
are therefore confronted with the pressure of introducing participatory elements into the decision-making process in addition to the existing representative democratic procedures [3], [4]. The degree to which individuals feel personally affected by a project often diverges from the "objective" or measurable consternation, e.g. local residents, which can be predicted by public or private project bodies [5]. A specific and comparatively well-researched phenomenon is the NIMBY (Not In My Backyard) behavior that has been observed in many conflicts surrounding public infrastructure [6]. The early integration of potentially affected citizens in planning processes may help to identify individual consternations and concerns, thereby preventing escalation processes. Psychological research emphasizes the role of trust in participatory processes [3]. The early integration of different stakeholders in the very early planning phase may avoid the consolidation of opposing coalitions and the formation of enemy images [1]. A specific challenge for participatory processes arises from their contradictory form of procedure: Although the possibilities to influence the project design are greatest during the early project phase, participation is often only envisaged for the later planning phases. The decreasing possibilities to influence the planning process in these later phases may lead to discontent among external stakeholders during the participation process and thus contribute to escalation. In the factory planning process, participation often only takes place with employees of the company. In many cases, external stakeholders are only involved if the participation of authorities, for example, is absolutely necessary in the context of approval procedures.

Compared to public project developers, private project bodies face an additional challenge. This challenge is particularly relevant in the case of construction projects in areas where local inhabitants are directly affected by the project, e.g. urban factories. Contrary to public projects, e.g. the construction of a public railway station, private projects rarely benefit the general public. The benefits of private projects are normally limited to private actors, whereas the costs must partially be borne by the general public, e.g. by local residents in the form of noise or air pollution or increased traffic. We argue that the unequal distribution of costs and benefits in the case of private projects increases the likelihood of resistance against the project by citizens and the risk of escalation. Our main argument is that the creation of general benefits by private project developers may decisively contribute to the approval of the project by external actors. In addition to the provision of individual financial compensations, which only benefit a limited number of actors, project developers should seek to create public benefits.

A second challenge relates to the different levels in the cost-benefit considerations [7]. The negative side effects of private construction projects, such as the building of a new production plant, often affect the local level only. Noise or air pollution are mostly limited to the local level, whereas the benefits in the form of economic gain are independent, i.e. they are transferred to the headquarters of the company. Even legally binding instruments, such as ecological compensation areas, are often created in other regions and thus do not benefit local residents. Accordingly, participatory processes must pay special attention to the local stakeholders and find ways to create private and public benefits at the local level, e.g. in the form of jobs or public goods. In Figure 1, these differences in costs and benefits between public and private projects are subsumed. 


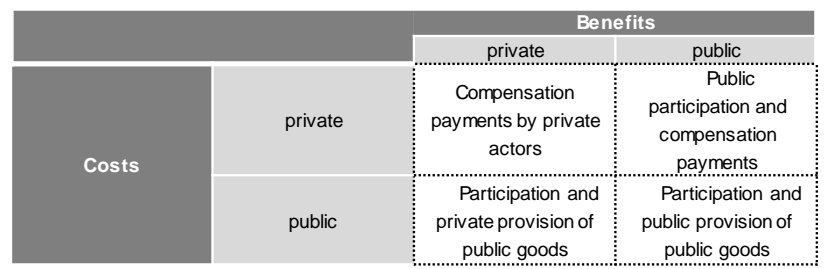

Figure 1: Cost-benefit considerations in public and private projects (own compilation)

To solve the depicted conflicts of interests, we propose a combination of compensation payments made specifically to affected citizens, the provision of public goods, and public participation that is already in the early planning phase. Private project developers can use participatory instruments, such as neighborhood dialogues or roundtables, to create a basis of trust with external stakeholders and identify concerns and reservations regarding the construction project. Based on the results of the participatory process, external stakeholders can jointly decide upon the design and selection of compensatory measures in the form of public goods. There are a number of examples of excellent stakeholder involvement in the successful construction of factories in urban areas. In these instances, external actors were involved in the early phases of the planning process.

To gain a deeper understanding of the dynamics between project developers and external actors during private construction projects, we will firstly analyze the status quo of participatory elements in the factory planning process (see section 2). To explore how both sides - planning bodies and external stakeholders - evaluate the current situation, we present preliminary results of a survey conducted in 2018 (see section 3). The survey results indicate that external stakeholders increasingly demand participation and expect project developers to address their concerns personally. In addition, we present a concept for the integration of stakeholders systematically and project-specifically in the context of factory planning (see section 4).

\section{Status quo of participatory elements in the factory planning process}

When considering participatory research, different forms of participation in factory planning can be identified. Within the framework of participation in factory planning projects, existing findings focus on the involvement and participation of employees. [8] The participation of external stakeholders is rarely, if at all, addressed in the relevant literature. The current research project (see ACKNOWLEDGMENT) was the first to systematically highlight the relevance of various stakeholder groups to the factory planning process as well as their impact on the resulting costs, time and quality of the factory planning project. A detailed and up-to-date overview of the role of participation in the factory planning process is provided by Dombrowski et al. [9] The so-called "participation paradox" is evident in the participation of both internal and external stakeholder groups (see Figure 2). 


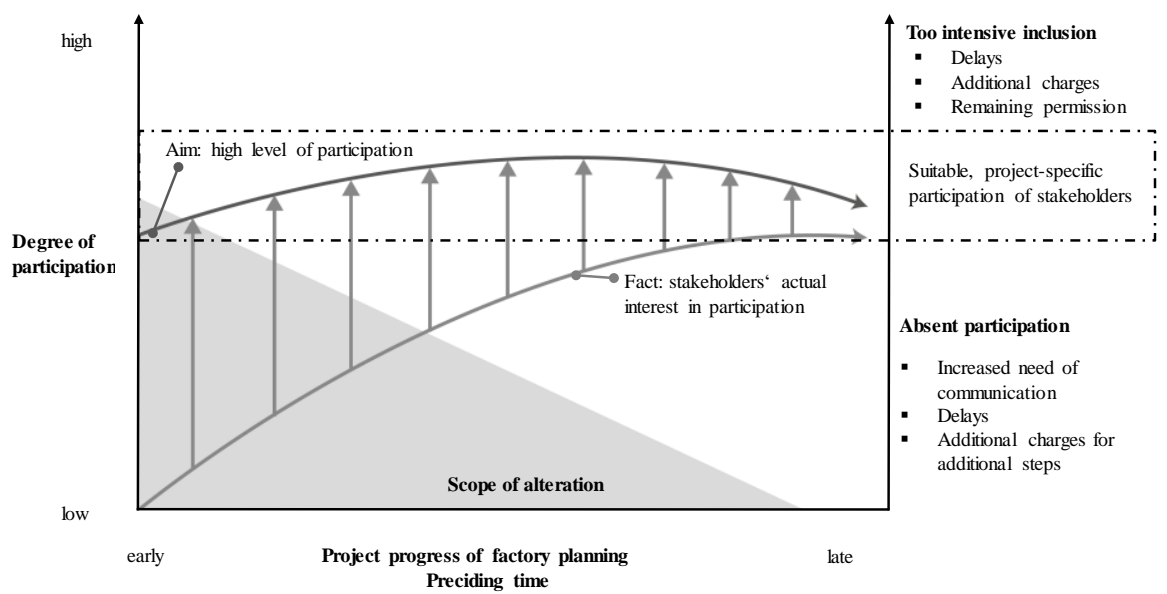

Figure 2: The participatory paradox of factory planning [9]

Accordingly, the actual interest of stakeholders in participating in the early phase of a factory project is very low. Stakeholder interest only increases as the project progresses. In the early phase of a project especially, the possibilities of influencing the project are highest and the resulting costs of change lowest. These findings already point to the necessity of establishing a systematic participation process. However, the degree of appropriate participation depends on the project and cannot usually be determined by companies. A lack of stakeholder participation in numerous projects usually leads to increased communication effort and delays in the factory project. Overly intensive participation results in additional costs and approval procedures. Here, too, project delays are likely. A higher complexity is added: Different process stages and their sub-processes within the framework of factory planning show different possibilities and potentials [9]

\section{Selected results of the studies}

Based on the problems described above (see section 2), several individual studies were carried out as part of the research project "Future Building Participation". The studies were conceived with the involvement of the project consortium with partners from planning offices, authorities, industry, and science. The survey was conducted throughout Germany. The studies are qualitative as well as quantitative surveys. Figure 3 summarizes further information on them. The quantitative studies are divided into two surveys (1). Within the framework of these two surveys, a total of 5,793 responses were collected within six months. Topic areas of the questions address the interaction between companies and stakeholders, the time and manner of integration, current obstacles and risks, as well as recommendations for participation. In addition to the current findings from the literature, the results of systematic analyses from a total of five case studies were used in the preparatory stage of the study (2). The results were supplemented and substantiated by ten expert interviews (3). The aim of the partial studies 
was to obtain a comprehensive overview of the current deficits, to concretize them and

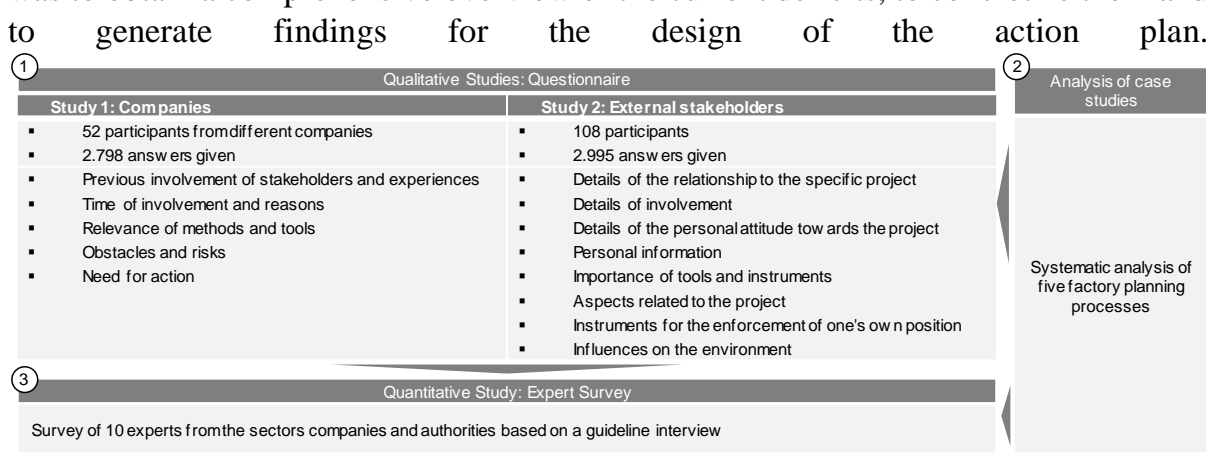

Figure 3: Overview of the studies carried out

To (1): The results of the two surveys clearly demonstrate the need for action. Overall, more than $50 \%$ of companies state that they do not yet have a system, guidelines or other processes for involving external stakeholders. Without the necessary system, the integration process runs without standards and is conducted in a purely subjective manner by the responsible employee. In these cases, successful participation is not guaranteed and results as a random event. Necessary fields of action are shown in Figure 4.

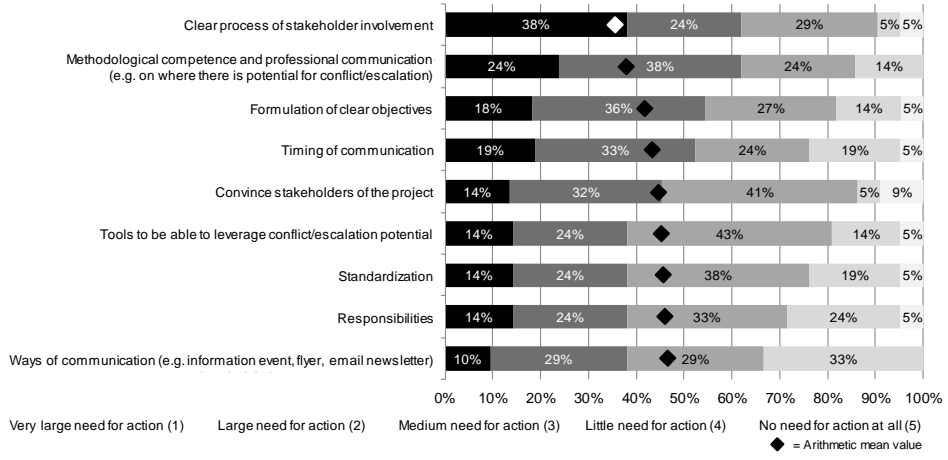

Figure 4: Need for action from the company perspective $(n=52)$

According to the survey, over $62 \%$ of the companies see a need for major action in a transparent process to involve the stakeholders. The participants' entire planning process shows considerable deficits due to the lack of participation standards, which can lead to escalations with external participants, higher costs and lower planning quality. Without this standardization, management of participation remains impossible. This is confirmed by the survey, which criticizes the lack of clear objectives as relevant fields of action. Another important area of action is the required methodological competence. The lack of competence is closely linked to the implementation of communication. In this context, the time of communication can be identified as a relevant field of action. To which needs the transparent process must be geared towards remains unclear at this 
point. In addition to the perspective of the company, a closer look at the external stakeholders is necessary. Figure 5 below shows the consequences that the surveyed actors would draw from mistaken participation.

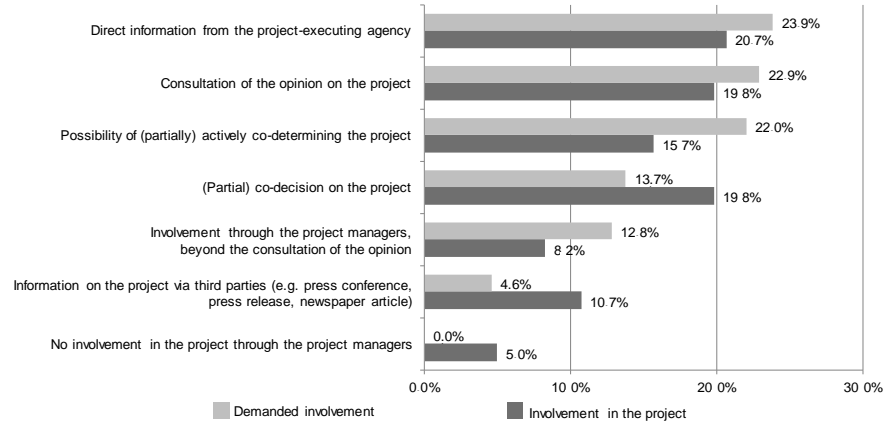

Figure 5: Desired and actual involvement in the project from stakeholder perspectives $(n=108)$

According to the respondents, greater participation in the planning process is required. Interestingly, the participants generally want a lower level of co-decision on the project. Rather, they would like to be informed directly by the project-executing agency. Having their opinions heard as well as the possibility of participating (partly) actively in the project are strongly pronounced wishes. These results play a major role in the design of the concept as they enable recommendations to be made on the degree of participation required.

To (2): As a result of the survey, the existing fields of action could be further concretized. On the one hand, relevant results are available. On the other hand, there is a lack of concrete technical content for the design of an action guideline. This is where the expert interviews come in. Partial results are summarized in Figure 7.

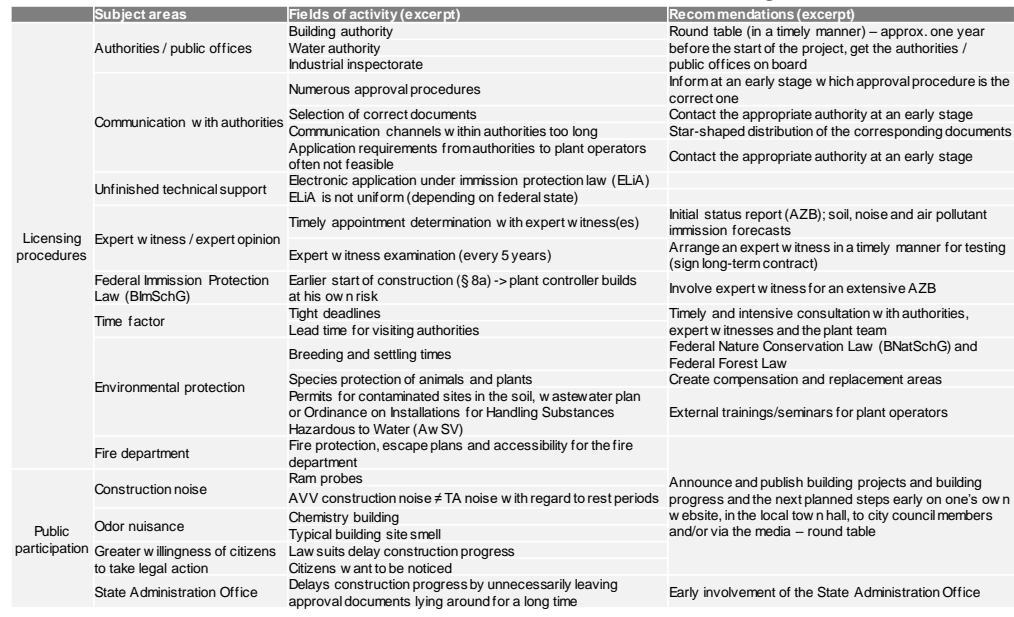

Figure 6: Structured results from the ten expert interviews (excerpt) 


\section{Concept}

The approach consists of transferring the collected findings into a practice-oriented guideline for action. This guideline is intended to facilitate the project-specific involvement of stakeholders in factory planning and construction projects. Based on the results (see section 3) and supported by the participants of the project consortium, the four following fields of action could be summarized: "sustainable planning", "frontloading", "transparency and visualization" and "stakeholder orientation". The structure concept of Lean production systems (VDI 2870) was used for the operational implementation of the structure concept. The concept offers an ideal structure for operationalizing fields of action; it is already familiar to numerous companies and has established itself in operational practice. The structure is shown in Figure 7.

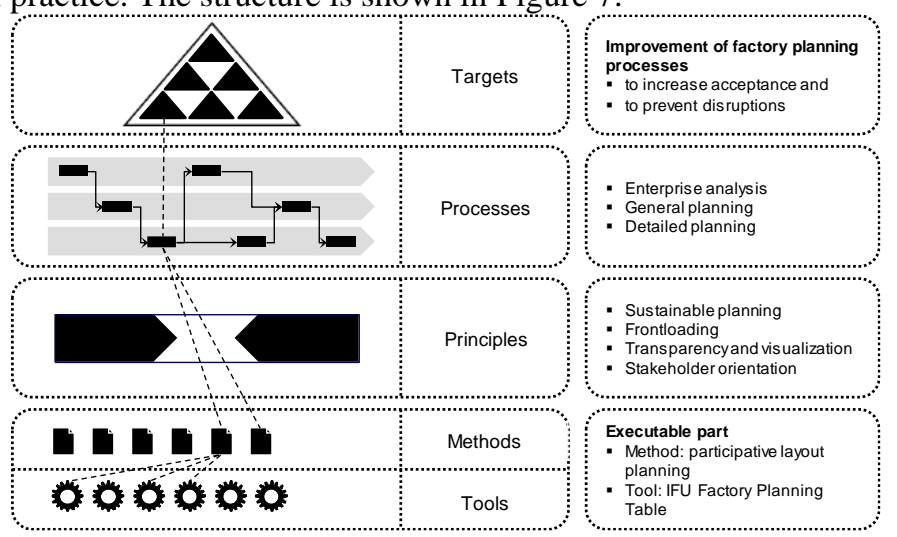

Figure 7: Structure of the Guide to Action (based on VDI 2870, [10])

\section{$5 \quad$ Summary and outlook}

The existing results provide the basis for the systematic integration of external stakeholders into the planning process of factories. In the future, it will be necessary to evaluate the methods and tools already identified for participation and to measure their influence on costs, time and quality. In addition, the concept must be fully validated in practice.

\section{ACKNOWLEDGMENT}

The research project "Integration of stakeholders to increase acceptance and prevent disruptions in planning and execution" (SWD-10.08.18.7-17.52) is funded by the research initiative "Zukunft Bau of the Federal Institute for Building, Urban and Space Research (BBSR) in the Federal Office for Building and Regional Planning Framework. The research project focuses on the degree of participation in the construction project in an entrepreneurial context. The aim of the research project is the early, tar- 
geted involvement of experts in construction and planning processes. The resulting increase in acceptance should help to avoid long-term stress and resulting delays. Relevant results of the research project are to be prepared in a comprehensive and practiceoriented action guide to support companies in the project-specific integration of stakeholders into their factory planning projects. The project takes place from 08/2017 to $07 / 2019$.

\section{References}

1. Vogeler CS, Bandelow NC (2018) Mutual and Self Perceptions of Opposing Advocacy Coalitions: Devil Shift and Angel Shift in a German Policy Subsystem. Review of Policy Research 35(5): 717-732. doi: 10.1111/ropr.12299

2. Wagschal U (2012) Die Volksabstimmung zu Stuttgart 21: Zwischen parteipolitischer Polarisierung und "Spätzlegraben". Der Bürger Im Staat 62(3): 168-173

3. Bandelow NC, Thies B (2014) Gerechtigkeitsempfindungen bei Großprojekten als Ursache von Konflikteskalationen? Vertrauen und Legitimität als moderierende Faktoren illustriert am Beispiel der Konflikte um die Erweiterung des Frankfurter Flughafens. Politische Psychologie (Journal of Political Psychology) 3(1): 24-37

4. Fink S, Ruffing E (2017) The Differentiated Implementation of European Participation Rules in Energy Infrastructure Planning. Why Does the German Participation Regime Exceed European Requirements? European Policy Analysis 3(2): 274-294. doi: 10.1002/epa2.1026

5. Lindloff K, Lisetska K, Eisenmann T et al. (2017) Regionale Betroffenheit in informellen Beteiligungsverfahren bei Infrastrukturprojekten. der moderne staat (dms)(1): 89-115

6. Di Nucci M, Brunnengräber A (2017) In Whose Backyard? The Wicked Problem of Siting Nuclear Waste Repositories. European Policy Analysis 3(3): 295323

7. Hornig E-C (2017) Airport Expansions and Public Protests-The Democratic Dilemma of Vertically Asymmetric Policies. European Policy Analysis 3(3): 324-342

8. Dombrowski U, Riechel C, Schulze S (2011) Enforcing employees participation in the factory planning process. In: 2011 IEEE International Symposium on Assembly and Manufacturing (ISAM). IEEE, pp 1-6

9. Dombrowski U, Karl A, Imdahl C (2018) The Role of Participation in the Factory Planning Process: 957-960

10. Verein Deutscher Ingenieure (2012) VDI 2870 Lean production systems Basic principles, introduction, and review: Part 1 